Research Article

\title{
An Analysis of Relationship between the Microfracture Features and Mineral Morphology of Granite
}

\author{
Meiben Gao $\left(\mathbb{D},{ }^{1,2}\right.$ Tianbin Li $\mathbb{D},{ }^{2}$ Junxun Zhu, ${ }^{3}$ Hongyu Yin, ${ }^{2}$ and Yongyi Yang ${ }^{1,4}$ \\ ${ }^{1}$ School of Emergency Science, Xihua University, Chengdu, Sichuan 610039, China \\ ${ }^{2}$ State Key Laboratory of Geohazard Prevention and Geoenvironment Protection, Chengdu University of Technology, Chengdu, \\ Sichuan 610059, China \\ ${ }^{3}$ Shandong Construction Engineering Quality Inspection and Testing Center Co., Ltd., Jinan, Shandong 250031, China \\ ${ }^{4}$ The Center of National Railway Intelligent Transportation System Engineering and Technology, \\ China Academy of Railway Sciences Corporation Limited, Beijing 100081, China
}

Correspondence should be addressed to Tianbin Li; ltb@cdut.edu.cn

Received 25 June 2021; Accepted 27 July 2021; Published 31 July 2021

Academic Editor: Guowen Xu

Copyright (C) 2021 Meiben Gao et al. This is an open access article distributed under the Creative Commons Attribution License, which permits unrestricted use, distribution, and reproduction in any medium, provided the original work is properly cited.

Using the techniques of X-ray diffraction, polarizing microscopy, uniaxial compression, and scanning electron microscopy (SEM), the relationships between the microfracture features and mineral morphology of granite were studied. The results showed that feldspar, quartz, and biotite are the main components of the granite samples in this study. Biotite has a self-shaped flake structure with perfect cleavage. K-feldspar has a lattice double crystal structure with two groups of cleavage. Plagioclase has a semi-selfshaped plate structure with two groups of cleavage. Quartz is prismatic or granular and exhibits noncleavage. The microfracture features of biotite are flaky with exfoliation, and flake cleavage fracture is mainly determined by its peculiar flaky cleavage. Feldspar (K-feldspar and plagioclase) is plate, layered, or two groups of cleavage and is also mainly determined by its peculiar two groups of cleavage. The microfracture features of quartz are highly irregular, with many randomly distributed intergranular and transgranular cracks, small particles or granule bulges, similar to quartz crystal, and this is due to the noncleavage feature of quartz itself. It is demonstrated that microfractures are preferentially ruptured along cleavage planes for these granite minerals under the action of external forces.

\section{Introduction}

The study of rock micromorphology is of great importance for understanding the failure mechanisms and mechanical behaviour of rock. In recent years, many achievements have been made in rock microresearch based on the scanning electron microscope (SEM) technique [1-4]. For example, according to rock failure morphology under dry and saturated conditions, Zhang et al. found that water had little influence on the crack development direction, but promoted the development of microcracks [5]. Through the study of crack and microstructure characteristics of shale, Zhong et al. revealed the micro-macro mechanism of shale [6]. Li and $\mathrm{Ni}$ concluded that macrofatigue damage of granite was caused by the propagation and coalescence of cracks at the microscale [7]. Zhang and Zhao and Liang et al. analysed the effect of loading rate on rock failure and found that more transgranular cracks occurred with increasing strain rate $[8,9]$. Yao et al. analysed the correlation between the geometrical characteristic and fracture energy of marble [10].

In contrast, some researchers also investigated the microbehaviours of rocks by using model tests and numerical methods. In this field, Jiang et al. established a perfect microcementation model by the systemic study of model tests [11] and then used the model to simulate the cementation between rock particles [12]. With the combination of models of bonded particles and smooth joints, an equivalent crystal model was employed to reveal the fracture mechanism and strength of granite from a microscopic view [13]. In addition, according to the microfeatures visible through SEM, the characteristic image of the granite 
microstructure can be obtained through a digital image processing method. Furthermore, with the development of numerical methods, the micromechanical characteristics and kinematic behaviours of rock grains can be analysed by those numerical methods, and these results reveals that cracks first generate at the interface, then in mica, and finally in feldspar and quartz $[14,15]$.

These findings, obtained from SEM, model tests, and numerical methods, focus predominantly on rock composition, natural microstructures, fracture morphology, microcrack fracturing, micromechanism, and micro-macro relationships, which are helpful in understanding rock mechanics. While rock is a natural assemblage of various mineral grains with different sizes, the size and morphology of each mineral grains undoubtedly affect their physical and mechanical properties [16]. Subsequently, grain size research studies on rocks were carried out [17]. Wong et al. found the peak strength decreased with the inverse square root of the mean grain size [18]. Hatzor et al. demonstrated that grain size alone cannot be used in correlation with ultimate strength; rather, the combination of both grain size and porosity controls the mechanical response of the rock [19]. Eberhardt et al. found that grain size had only a minor effect on new crack initiation, but did have a significant effect on crack propagation. Furthermore, they pointed out that rock strength decreased with increasing grain size, not by inducing crack initiation at lower stresses, but through a process where longer cracks propagating along longer planes of weakness coalesced at lower stresses [20]. Besides, Lan et al. found that the grain size distribution in brittle rocks was a good index to represent the microheterogeneity [21].

Certain types of rocks, such as granites, have similar composition minerals. Although their distribution and grain size differ, their mineral morphology is certain. Links between microfracture features and mineral morphology are rarely reported. In this research, granite compositions were measured using X-ray diffraction. The microfeatures of the granite after uniaxial compression were observed by scanning electron microscopy (SEM). This paper aims to explore the relationships between the microfracture features and mineral morphology of granite.

\section{Experimental Tests}

2.1. Description of Rock Specimens. Granite is an important raw material in industrial applications and is a widely distributed rock in the Earth's crust. It has applications in areas such as metallurgy, building materials, chemical industry, and agriculture. The granite used in this research was collected from the Gaoligongshan tunnel at a depth of $680 \mathrm{~m}$ in Baoshan city, Yunnan province, China. These specimens are grey in nature. Testing specimens have uniform texture, their average density is $2.65 \mathrm{~g} / \mathrm{cm}^{3}$, and the mean uniaxial compressive strength is $90 \mathrm{MPa}$.

2.2. Testing Facilities and Testing Procedure. The facilities used in this study involve an X-ray diffractometer (DMAX3C made in Japan), polarizing microscope (Nikon
LV100POL, shown in Figure 1(a)), scanning electron microscope (Hitachi S-3000N, shown in Figure 1(b)), and uniaxial compression test machine (MTS815, shown in Figure 1(c)).

Firstly, we checked the original features of granite by $\mathrm{X}$-ray diffraction and polarizing microscope experiment. The general morphological characteristics and arrangement of particles were determined using a polarizing microscope with a rock sheet (area $22 \times 22 \mathrm{~mm}$ and thickness $0.03 \mathrm{~mm}$ ). Meanwhile, to determine the mineral composition accurately, three small blocks were collected from different rock samples and ground into powder of approximately $5 \mathrm{~mm}$. Then, we placed the powder in the diffractometer groove and covered it with a glass sheet to initiate this test.

Secondly, uniaxial compression tests were conducted using a stiff load frame with a closed-loop servo-control system (MTS815) at the Rock Mechanics Laboratory at the State Key Laboratory of Geohazard Prevention and Geoenvironment Protection at the Chengdu University of Technology. The loading procedure in these experiments followed the International Society of Rock Mechanics (ISRM) guidelines. Specifically, $1 \mathrm{kN}$ force was preloaded to make the rock sample fixed; then, axial loading was carried out at the loading rate of $0.1 \mathrm{~mm} / \mathrm{min}$ until the specimen attains failure.

Finally, the SEM tests were carried out. The specimens for the SEM tests were typical blocks selected from the rock samples after the uniaxial compression tests. The microfracture features were observed by a set of rock sheets (area $10 \times 10 \mathrm{~mm}$ and thickness $3 \mathrm{~mm}$ ) after the process of cutting, grinding, and coating.

\section{Mineral Characteristics of Granite}

3.1. Mineral Composition. The constituent mineralogical components of granite and the composition of the granite are listed in Table 1. The mean components are feldspar (plagioclase $31 \%$ and K-feldspar 11\%), quartz (25\%), biotite $(25 \%)$, chlorite $(4 \%)$, tremolite $(4 \%)$, and pyrite $(2 \%)$.

3.2. Mineral Morphology Features. According to the polarizing microscope flake experiment results (Figure 2 and Table 2), biotite is self-shaped flake, with a set of perfect cleavage, yellowish brown-brownish green, with late chloritization, and a grain size in the range of $0.4-1.0 \mathrm{~mm}$. Quartz has an aggregate distribution (prismatic and granular), mainly around feldspar, with a grain size in the range of $0.2-0.7 \mathrm{~mm}$, which can reach up to $1.5 \mathrm{~mm}$. Alkali feldspar (K-feldspar) exhibits a lattice double crystal structure or perthitic texture, with the grain size of most grains below $2 \mathrm{~mm}$, in the range of $1-5 \mathrm{~mm}$. Some creep metasomatisms distribute around the local edge. The secondary alteration in the later stage is mainly characterized by sodium feldspar and weak kaolinite. Plagioclase (mainly, oligoclase-andesine) is a semi-self-shaped plate, with a cluster twin and girdle structure and grain size in the range of $0.5-2.0 \mathrm{~mm}$, which can reach up to $3.0 \mathrm{~mm}$. The secondary alteration in the later stage is mainly weak chloritization or clay, and sericitization of a few grains is obvious. 


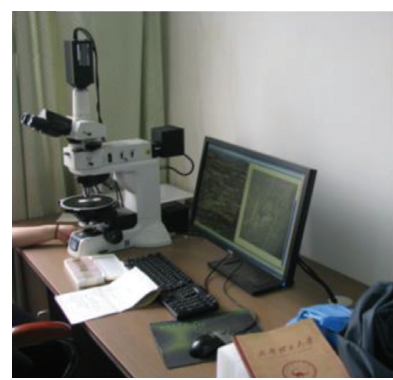

(a)

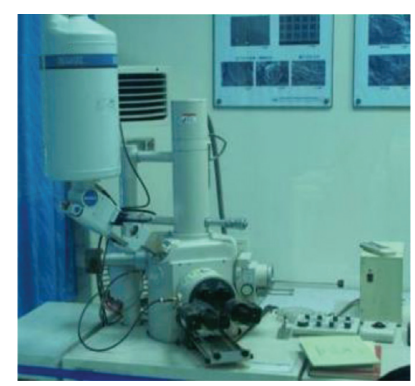

(b)

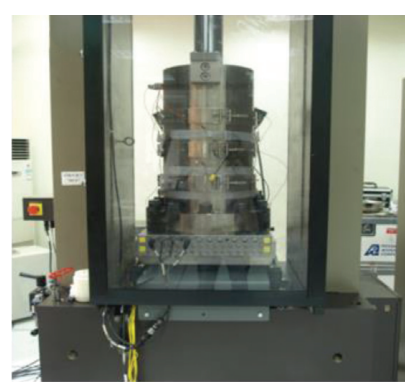

(c)

Figure 1: Testing facilities. (a) Nikon LV100POL polarizing microscope. (b) Hitachi S-3000N scanning electron microscope. (c) MTS815 rock mechanics testing machine.

TABLe 1: Mineralogical composition of the tested material (weight \%).

\begin{tabular}{lccccccc}
\hline Sample ID & Biotite & Quartz & K-feldspar & Plagioclase & Chlorite & Tremolite & Pyrite \\
\hline G1 & 22 & 25 & 14 & 29 & 4 & 4 & 2 \\
G2 & 27 & 22 & 9 & 32 & 3 & 4 & 4 \\
G3 & 25 & 23 & 10 & 32 & 4 & 4 \\
Mean & 25 & 23 & 11 & 31 & 4 & 4 \\
\hline
\end{tabular}

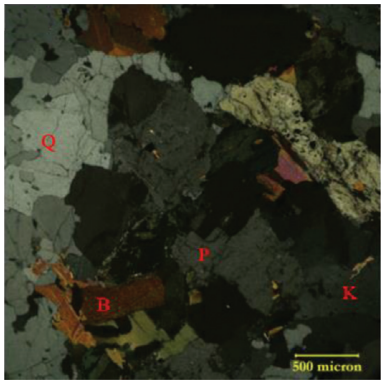

(a)

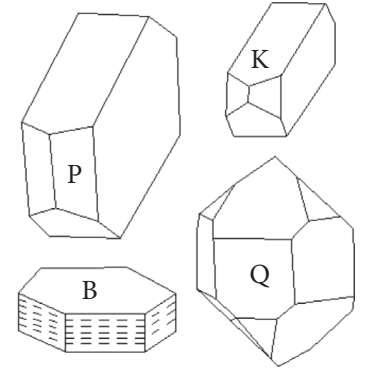

(b)

FIgure 2: Microfeatures of granite. (a) Polarizing microscope features. (b) Mineral morphology (B: biotite, Q: quartz, K: K-feldspar, and P: plagioclase).

TABLE 2: Main mineral morphology features of granite.

\begin{tabular}{|c|c|c|c|c|c|}
\hline Mineral & $\begin{array}{l}\text { Particle size } \\
\quad(\mathrm{mm})\end{array}$ & Particle structure & Crystal form & Cleavage & $\begin{array}{c}\text { Mohs } \\
\text { hardness }\end{array}$ \\
\hline Biotite & $0.4-1.0$ & $\begin{array}{c}\text { Self-shaped flake structure, perfect } \\
\text { cleavage }\end{array}$ & Flake & Perfect cleavage & 2.5 \\
\hline Quartz & $0.2-1.5$ & Aggregate distribution, noncleavage & Prismatic and granular & $\begin{array}{l}\text { Noncleavage and conchoidal } \\
\text { fracture }\end{array}$ & 7 \\
\hline K-feldspar & $1.0-5.0$ & $\begin{array}{l}\text { Lattice double crystal structure and } \\
\text { perthitic texture }\end{array}$ & $\begin{array}{l}\text { Thick plate and short } \\
\text { columnar }\end{array}$ & Two groups of cleavage & 6 \\
\hline Plagioclase & $0.5-3.0$ & $\begin{array}{l}\text { Semi-self-shaped plate, cluster twin, and } \\
\text { girdle structure }\end{array}$ & Plate & Two groups of cleavage & $6-6.5$ \\
\hline
\end{tabular}

\section{Microfeature and Analysis}

4.1. Microfeatures of Black Mica. As shown in Figure 3(a), the mineral structure is loose, with pores and microcracks. The fracture is flaky, and the outer edge is uneven. A large number of transgranular cracks cut the mineral crystals into sheet-like crystal slices of different sizes, which are randomly distributed.

As shown in Figure 3(b), the contact state of mineral particles is good. The fracture is flaky, and the outer edge is uneven. On the right side of the picture, the fracture characteristics are obviously flaky, and there is some grain particles' debris on the surface. The fracture on the upper left side is smooth and flat and is presumed to be a cleavage fracture along feldspar.

As shown in Figure 3(c), the contact state of mineral particles is good. The fracture surface is flat, and some biotite minerals show exfoliation fracture or parallel distortion along cleavage. The interface cracks develop well along the 


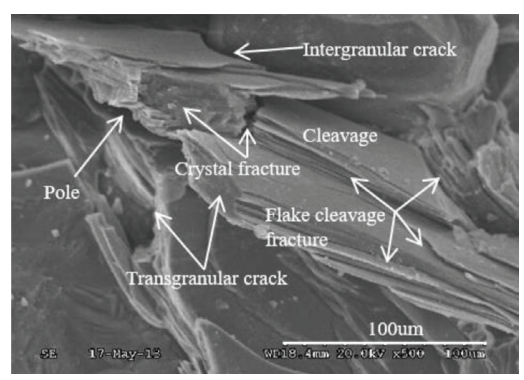

(a)

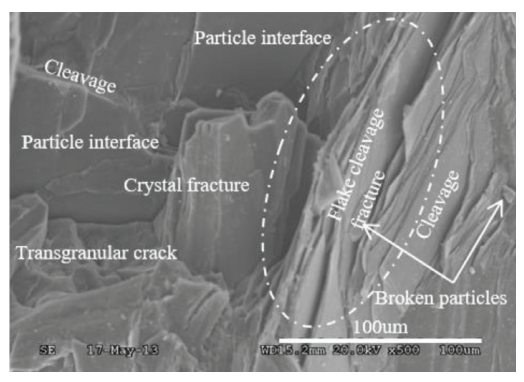

(b)

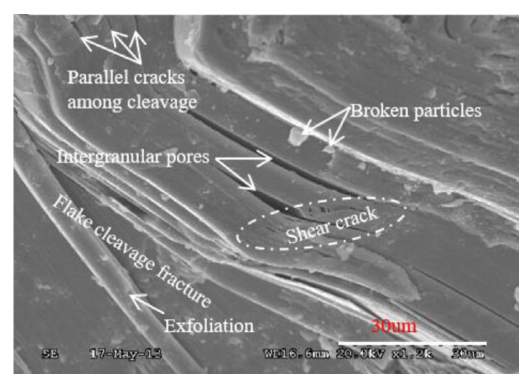

(c)

FIGURE 3: Main microfeatures of biotite. $(\mathrm{a}-\mathrm{c})$ Flaky fractures in granite samples.

long axis direction of the crack. Parts of the cracks terminate in the interior of the grains, forming an in-crystal crack. Moreover, parts of the cracks penetrate the whole mineral grains, forming a through-crystal crack resulting in flaky peeling. The surfaces of the in-crystal cracks and throughcrystal cracks are smooth and flat. There is some grain particles' debris on the surface.

According to Figure 3, the microfracture features are flaky, exfoliation, and exhibits flake cleavage fracture. The combination of this and the mineral morphology show that only biotite is flake; feldspar is thick plate, plate, or short columnar; and quartz is prismatic or granular; thus, flaky rupture may only occur in flaky biotite minerals. Furthermore, the cleavage characteristics of granite minerals show that feldspar and quartz are two groups of cleavage and noncleavage or conchoidal fracture, respectively, which is inconsistent with the flake. In contrast, biotite is characterized by extreme perfect cleavage and flake and undergoes flaky damage under loading.

It is concluded that these flaky fractures in these granite samples may only occur in biotite mineral particles. On the basis of these features, the rupture characteristics of the biotite can be determined.

4.2. Microfeatures of Feldspar. As shown in Figure 4(a), the structure is relatively compact. Pores have not developed, and the original cracks are mostly in a closed state. The contact state of the mineral particles is good. The fracture is mainly transgranular, which is plate-like and the outer edge is rough rather than smooth. The particle interface is flat. Some cracks crack along the cleavage plane, and the surface is smooth. A number of tiny broken grain particles are distributed over the surface.

As shown in Figure 4(b), the structure is compact with limited pores and original cracks. The fracture is mainly along the cleavage with a smooth, layered, or plate surface. There are some small broken particles.

As shown in Figure 4(c), the structure is compact. There are no pores and original cracks. The contact state of mineral particles is good. Two main shear cracks may fracture along the two groups of cleavage, and their outer edge is uneven but smooth. The surface is without scratches and has no small particles. It is assumed that these fractures occurred within the feldspar particles along the cleavage.
According to Figure 4, the microfracture features are plate, layered, or two groups of cleavage, which is largely different from the fracture feature of biotite (flaky, exfoliated, and flake cleavage fracture). Compared with biotite flaky, these fractures have a certain thickness, and the fracture surface along the cleavage plane is flat and smooth, with good extension and plate-like rupture. The fracture features show the peculiar properties related to the two groups cleavage. These features, combined with the mineral morphology and cleavage characteristics of granite minerals, show that only feldspar has the two groups of cleavage, biotite is flaky, and quartz is prismatic or granular; thus, the plate, layered, or two groups of cleavage ruptures, with twoway extension, may only occur in feldspar minerals.

It is concluded that the plate, layered, or two groups of cleavage rupture fractures in these granite samples may only occur in feldspar mineral particles, and on the basis of these features, the rupture characteristics of the feldspar can be determined accordingly.

4.3. Microfeatures of Quartz. As shown in Figure 5(a), the mineral structure is loose, with many randomly distributed microcracks. The fracture surface is extremely uneven. Microcracks developed well, and they are mainly transgranular cracks with an uneven but relatively smooth surface. The right side of the picture shows a large number of messy small mineral particles.

As shown in Figure 5(b), a large number of small particles of different sizes are distributed irregularly over the surface. The presence of numerous intergranular and transgranular cracks causes breakage of the mineral crystals.

As shown in Figure 5(c), the fracture surface is extremely uneven, and there is a certain lamination phenomenon in the upper left corner, which is presumed to be a peculiar fracture in the biotite. There are many intergranular and transgranular cracks with uneven outer edges. The granule bulge in the middle, which has a smooth surface, is similar to the quartz crystal in Figure 2(b), and there is no obvious cleavage fracture surface.

According to Figure 5, the microfracture features are highly irregular, with many randomly distributed intergranular and transgranular cracks, small particles, or granule bulges, showing limited links to the regular cleavage. These fractures are not closely related to the exfoliation and flaky 


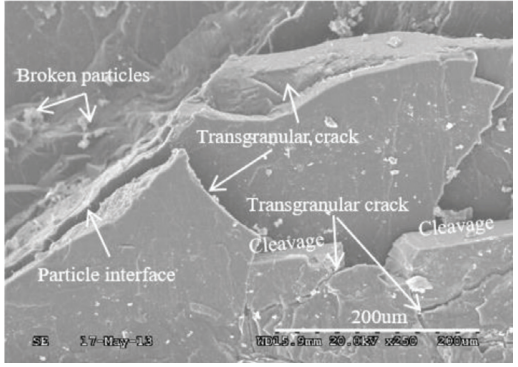

(a)

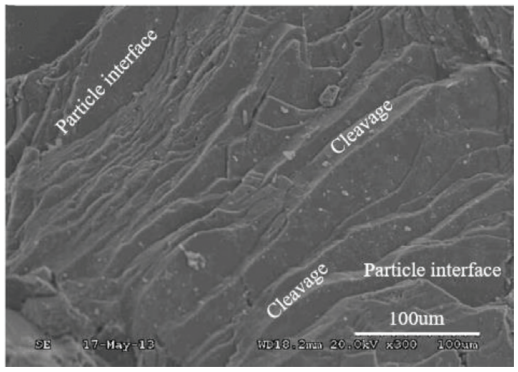

(b)

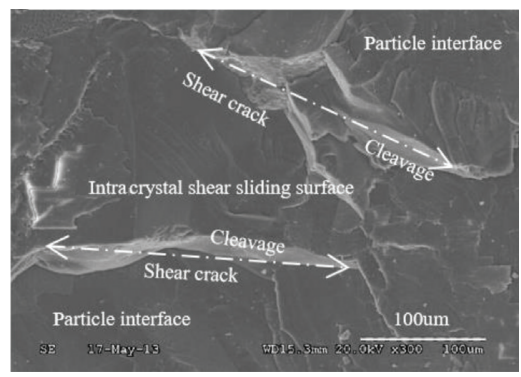

(c)

Figure 4: Main microfeatures of feldspar. (a, b) Plate or layered rupture fractures in granite samples. (c) Two groups of cleavage. Rupture fractures in granite samples.

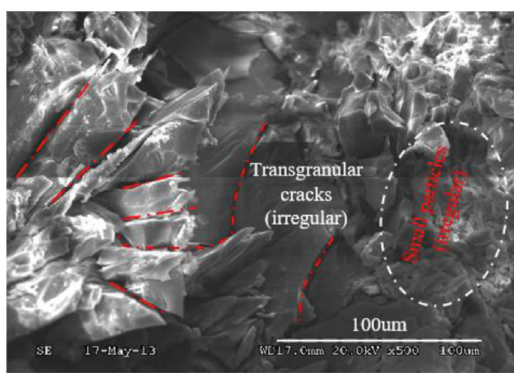

(a)

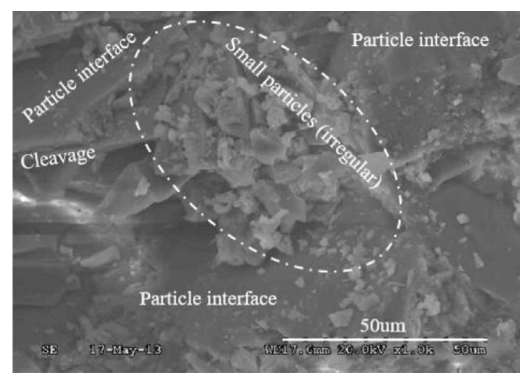

(b)

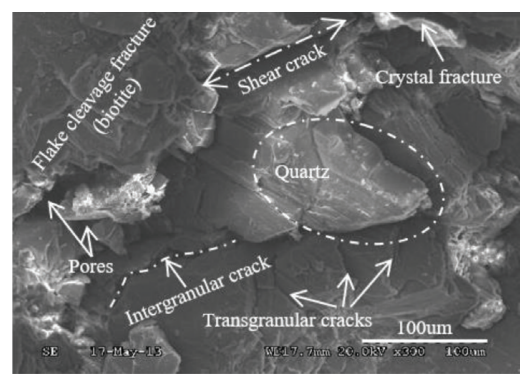

(c)

FIgURE 5: Main microfeatures of quartz. (a) Irregular, with many randomly distributed intergranular and transgranular cracks in granite samples. (b) Irregularly distributed particles in granite samples. (c) Granule bulges rupture fractures in granite samples.

characteristics of biotite and the characteristics of feldspar plate, layered, or two groups of cleavage fracture. Combining with the mineral morphology and cleavage characteristics of granite minerals, only quartz is prismatic, granular, and noncleavage; biotite is flaky; feldspar is thick plate, plate, or short columnar. Thus, these fractures that are not based on inherent cleavage may occur only in prismatic and noncleavage quartz minerals.

Above all, it is concluded that these fractures that are not based on inherent cleavage in these granite samples may only occur in quartz mineral particles, and on the basis of these features, the rupture characteristics of the quartz can be determined accordingly.

\section{Conclusions}

To study the relationship between the microfracture features and mineral morphology of granite, $\mathrm{X}$-ray diffraction, polarizing microscopy, uniaxial compression, and SEM tests were conducted. Based on the experimental results and observations of the microfracture features and mineral morphology, the following findings are obtained. The main components and the compositions of the granite samples in this study are feldspar (plagioclase $31 \%$ and $\mathrm{K}$-feldspar $11 \%$ ), quartz (25\%), and biotite (25\%). Biotite has a self-shaped flake structure, flake, with perfect cleavage. K-feldspar has a lattice double crystal structure and perthitic texture, thick plate, or short columnar, with two groups of cleavage. Plagioclase has a semi-self-shaped plate, cluster twin and girdle structure, plate, with two groups of cleavage. Quartz has an aggregate distribution, prismatic, and granular, with noncleavage or conchoidal fracture. The SEM results show that the microfracture features of biotite are flaky, exfoliation, and flake cleavage fracture, and these flaky fractures are the peculiar characteristics of biotite determined mainly by its cleavage. Feldspar (K-feldspar and plagioclase) has a plate structure, layered or two groups of cleavage, and these fracture features are also the peculiar characteristics of feldspar that are determined mainly by its cleavage. The microfracture features of quartz are highly irregular, with many randomly distributed intergranular and transgranular cracks, small particles, or granule bulging similar to quartz crystal; however, this is due to the noncleavage feature of quartz itself. These analyses demonstrate that microfractures are preferentially ruptured along cleavage planes for granite minerals under the action of external forces. The results of this study provide some reference value for the analysis of rock fracture mechanisms.

It is necessary to point out that the relationship between microfracture features and mineral morphology is the primary work for rock mechanics in terms of grain size. The final fracture and fracture pattern of rock samples are related to many factors, such as mineral composition, mineral morphology, mineral size, mineral distribution, mineral content, and interaction between mineral particles. Further research can be carried out from these two aspects: the fracture sequence of minerals and fracture process in terms of grain size. 


\section{Data Availability}

All the data used to support the findings of this study are included within the article.

\section{Conflicts of Interest}

The authors declare no conflicts of interest.

\section{Acknowledgments}

This research was supported by the National Natural Science Foundation of China (nos. U19A20111, 41772329, and 41230635), the On-Campus Talent Introduction Project in Xihua University (no. Z201125), and the Center of National Railway Intelligent Transportation System Engineering and Technology, China Academy of Railway Sciences (contract no. RITS2021KF04).

\section{References}

[1] M. L. Batzle, G. Simmons, and R. W. Siegfried, "Microcrack closure in rocks under stress: direct observation," Journal of Geophysical Research, vol. 85, no. B12, pp. 7072-7090, 1980.

[2] X. Y. Wu, P. Baud, and T. F. Wong, "Micromechanics of compressive failure and spatial evolution of anisotropic damage in Darley Dale sandstone," International Journal of Rock Mechanics and Mining Sciences, vol. 37, no. 1, pp. 143-160, 2000.

[3] M. J. Heap and D. R. Faulkner, "Quantifying the evolution of static elastic properties as crystalline rock approaches failure," International Journal of Rock Mechanics and Mining Sciences, vol. 45, no. 3, pp. 564-573, 2008.

[4] W. Zhu, P. Baud, S. Vinciguerra, and T. F. Wong, "Micromechanics of brittle faulting and cataclastic flow in Alban Hills tuff," Journal of Geophysical Research Atmospheres, vol. 116, no. B6, pp. 1-23, 2011.

[5] Y. B. Zhang, P. Liang, X. X. Liu, S. J. Liu, and B. Z. Tian, "Microstructure characteristics of rock burst fracture," Journal of Liaoning Technical University: Natural Science, vol. 34, no. 5, pp. 561-566, 2015.

[6] J. H. Zhong, S. X. Liu, Y. S. Ma, C. M. Yin, C. L. Liu, and Z. X. Li, "Macro-fracture mode and micro-fracture mechanism of shale," Petroleum Exploration and Development, vol. 42, no. 9, pp. 242-250, 2015.

[7] X. J. Li and X. H. Ni, "Test on meso-damage characteristic of granite mineral crystals under cyclic load," Bulletin of Science and Technology, vol. 31, no. 4, pp. 83-87, 2015.

[8] Q. B. Zhang and J. Zhao, "Effect of loading rate on fracture toughness and failure micromechanisms in marble," Engineering Fracture Mechanics, vol. 102, no. 2, pp. 288-309, 2013.

[9] C. Y. Liang, S. R. Wu, and X. Li, "Research on micro-mseo characteristics of granite fracture under uniaxial compression at low and intermediates strain rates," Chinese Journal of Rock Mechanics and Engineering, vol. 34, no. s1, pp. 2977-2986, 2015.

[10] S. F. Yao, Z. N. Zhang, X. R. Ge, Y. P. Qiu, and J. M. Xu, "Correlation between fracture energy and geometrical characteristic of mesostructure of marble," Rock and Soil Mechanics, vol. 37, no. 8, pp. 2341-2346, 2016.

[11] M. J. Jiang, Y. G. Sun, L. Q. Li, and H. H. Zhu, "Contact behavior of idealized granules bonded in two different interparticle distances: an experimental investigation," $M e$ chanics of Materials, vol. 55, pp. 1-15, 2012.

[12] M. J. Jiang, Y. G. Sun, and Q. J. Yang, "A simple distinct element modeling of the mechanical behavior of methane hydrate-bearing sediments in deep seabed," Granular Matter, vol. 15, no. 2, pp. 209-220, 2013.

[13] Y. Zhou, Y. T. Gao, S. C. Wu, Q. Yan, and H. Sun, "An equivalent crystal model for mesoscopic behaviour of rock," Chinese Journal of Rock Mechanics and Engineering, vol. 34, no. 3, pp. 511-519, 2015.

[14] S. J. Miao, Z. J. Yang, C. Long, and F. H. Ren, "Micro-mechanical characteristics and cracks revolution laws of migmatitic granite under different loading conditions," Journal of Jiangsu University (Natural Science Edition), vol. 33, no. 4, pp. 469-473, 2012.

[15] Y. C. Yin, T. B. Zhao, Y. L. Tan, and F. H. Yu, "Reconstruction and numerical test of the mesoscopic model of rock based on Otsu digital image processing," Rock and Soil Mechanics, vol. 36, no. 9, pp. 2532-2540, 2015.

[16] H. C. Heard, "Thermal expansion and inferred permeability of climax quartz monzonite to $300^{\circ} \mathrm{C}$ and $27.6 \mathrm{MPa}$," International Journal of Rock Mechanics and Mining Science \& Geomechanics Abstracts, vol. 17, no. 5, pp. 289-296, 1980.

[17] J. T. Fredrich, B. Evans, and T.-F. Wong, "Effect of grain size on brittle and semibrittle strength: implications for micromechanical modelling of failure in compression," Journal of Geophysical Research, vol. 95, no. B7, pp. 10907-10920, 1990.

[18] R. H. C. Wong, K. T. Chau, and P. Wang, "Microcracking and grain size effect in Yuen Long marbles," International Journal of Rock Mechanics and Mining Science \& Geomechanics Abstracts, vol. 33, no. 5, pp. 479-485, 1996.

[19] Y. H. Hatzor, A. Zur, and Y. Mimran, "Microstructure effects on microcracking and brittle failure of dolomites," Tectonophysics, vol. 281, no. 3-4, pp. 141-161, 1997.

[20] E. Eberhardt, B. Stimpson, and D. Stead, "Effects of grain size on the initiation and propagation thresholds of stress-induced brittle fractures," Rock Mechanics and Rock Engineering, vol. 32, no. 2, pp. 81-99, 1999.

[21] H. X. Lan, C. D. Martin, and B. Hu, "Effect of heterogeneity of brittle rock on micromechanical extensile behavior during compression loading," Journal of Geophysical Research, vol. 115, no. B1, pp. 1-14, 2010. 